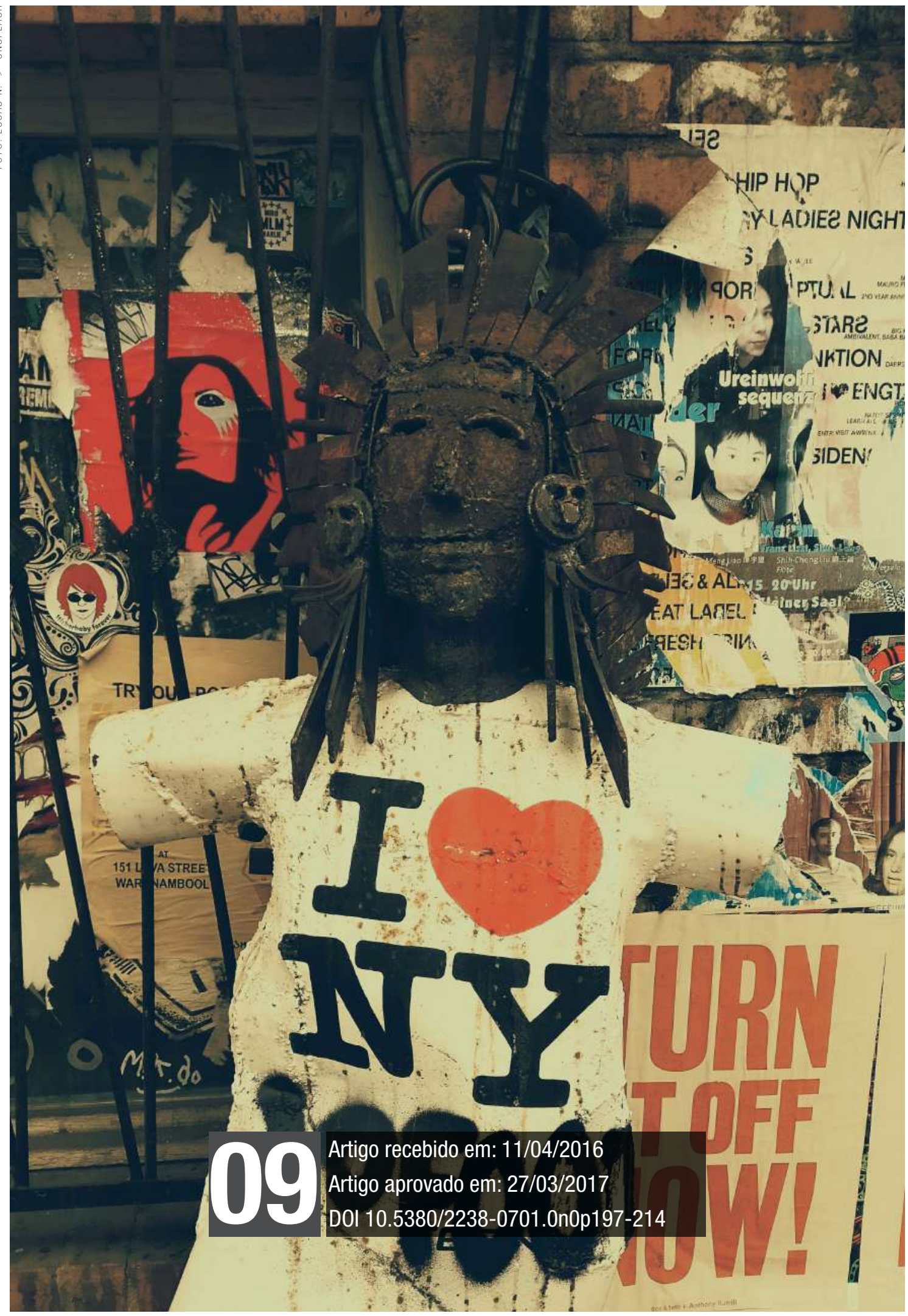


Enunciador. Estesis. Figuratividade. Mídia impressa. 


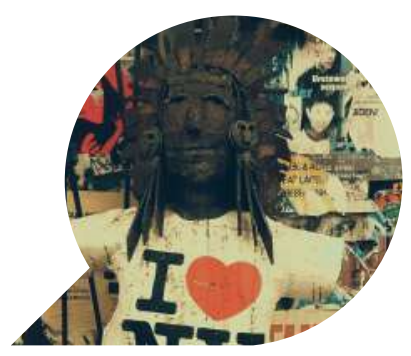

\title{
Sujeitos em estesis: uma expressão da figuratividade em Veja
}

\author{
Subject in esthesis: an expression of figurativity \\ in Veja magazine
}

Los sujetos en estesis: una expresión de la figuratividad
en la semanaria Veja

RUBEN DARGÃ HOLDORF ${ }^{1}$

Resumo: Este artigo traduz as relações entre os títulos de capa e das páginas amarelas da maior semanária brasileira. Seguindo alguns dos postulados das semióticas greimasiana e discursiva, a formação de novos significados na construção de sentidos revela as intenções do destinador-manipulador da revista ao fazer valer sua programação sobre os enunciatários-leitores. Para exemplificar os conceitos exarados de Algirdas Greimas e Eric Landowski, serão analisados dois recortes: o primeiro relaciona o presidente norte-americano Barack Obama e o arcebispo de Olinda, José Cardoso Sobrinho; o segundo confronta o sujeito "derretimento da calota polar" com o então ministro da Justiça, Tarso Genro. Busca-se, assim, perceber os efeitos de sentido nessa relação dialógica entre sujeitos.

\footnotetext{
${ }^{1}$ Doutor em Comunicação e Semiótica (PUC-SP), é graduado em Comunicação Social/Jornalismo (UFPR). Coordena o Bacharelado em Jornalismo do Centro Universitário Adventista de São Paulo (Unasp), em Engenheiro Coelho. Lattes: http://lattes.cnpq.br/9023786250983747. E-mail: ruben. holdorf@unasp.edu.br.
} 
Palavras-chave: Enunciador; Estesis; Figuratividade; Mídia impressa; Semiótica.

Abstract: This article reflects the relationships between the cover headlines and yellow pages report of the Brazilian major weekly newsmagazine. According to some of the postulates of Greimasian and discourse semiotic, the formation of new significance in the construction of meanings reveals the magazine sender-manipulator's intentions to enforce its programming on the enunciatee-readers. In order to illustrate the concepts drawn up by Algirdas Greimas and Eric Landowski, two clippings will be analyzed: the first relates the US President Barack Obama to the archbishop of Olinda, José Cardoso Sobrinho; the second confronts the subject "melting of the polar cap" with the Minister of Justice at the time, Tarso Genro. Therefore, the aim is to perceive the sense effects in this dialogical relation between subjects.

Keywords: Enunciator; Esthesis; Figurativity; Printed media; Semiotics.

Resumen: Este artículo traduce las relaciones entre los títulos de la primera página e de las páginas amarillas de la mayor semanária brasileña. Siguiendo algunos de los postulados de las semióticas greimasiana y discursiva, la formación de nuevos significados en la construcción de los sentidos revela las intenciones del destinador-manipulador de la publicación para efectuar su programación en los enunciatarios-lectores. Para ejemplificar los conceptos desarrollados por Algirdas Greimas y Eric Landowski, se analizaron dos recortes: el primer se refiere al presidente norteamericano Barack Obama y el arzobispo de Olinda, José Cardoso Sobrinho; el segundo carea el sujeto "derretimiento de los casquetes polares" con el ministro de Justicia en la ocasión, Tarso Genro. El objetivo es percibir los efectos de sentido en la relación de diálogo entre los sujetos.

Palabras clave: Enunciador; Estesis; Figuratividad; Medios impressos; Semiótica. 


\section{Panorama inicial}

Em artigo publicado pela Acta Científica (HOLDORF, 2009, p. 2538), registraram-se os métodos ortodoxos utilizados pela revista brasileira Veja na relação dialógica entre os títulos de capa e das páginas amarelas. Por meio dessa metodologia, verificou-se, então, o modo pelo qual se projeta a visão de mundo da política editorial da revista, comprovando-se, também, o conteúdo doutrinário de seu manual de redação. Como embasamento teórico, recorreu-se na ocasião a referenciais das teorias da comunicação, tais como Manuel Chaparro, José Marques de Melo e Michael Kunczik. Com o objetivo de reforçar a presença dialógica entre os títulos de capa e das páginas amarelas em Veja para este artigo, investigou-se o funcionamento do conceito da engenharia do discurso ${ }^{1}$ sob os olhares da semiótica francesa ou greimasiana - ou ainda ciência dos sentidos - e da semiótica discursiva.

$\mathrm{O}$ interesse pelos diálogos entre os títulos de capa e das páginas amarelas de Veja como objeto de pesquisa surgiu em 2007, durante o mestrado, estimulado pelo orientador Franklin Valverde, o primeiro pesquisador a perceber tal possibilidade. Depois de ler Conti (1999, p. 70 e 100), certifiquei-me mais uma vez do poder de manipulação do destinador de Veja sobre o enunciador e deste sobre o enunciatário nas entrevistas das páginas amarelas. Ao mesmo tempo em que o destinador se ressentia quando contestado pelo enunciador, ${ }^{2}$ este articulava a razão para revitalizar o enunciado.

Segundo o Instituto Verificador de Circulação (IVC, 2015), Veja conserva uma tiragem superior a um milhão e cem mil exemplares, tor-

\footnotetext{
${ }^{1}$ Engenharia do discurso: a mídia convoca seus públicos por meio de palavras de ordem. Unidade elementar da linguagem, a palavra de ordem é o enunciado que funciona em um dado campo de poder, de acordo com os códigos e sua eficácia, simbolizando certo real. Trata-se da narrativa costurada no espaço do ponto nodal, a construção da cadeia discursiva interna midiática, que se apropria da aceitação de grandes massas. Palavras de ordem têm a capacidade de camuflar ou esclarecer determinadas situações, inclusive paradigmas que explicam preconceitos e estereótipos. 0 Outro passa a ser tratado com desconfiança e medo. A engenharia do discurso visa a identificar essas novas forças que tentam se hegemonizar, bem como seus dispositivos, totalizando-se em pontos nodais, e analisar como tais antagonismos aperfeiçoam a compreensão da relação amigo-inimigo. Além disso, é preciso entender o modo pelo qual o discurso se encarna no espaço do Mesmo - ou do "eu" e do "nós" - e constrói a figura no espaço do Outro - do "ele" ou "eles" -, determinando-o como alguém a ser aproximado, tolerado ou afastado (HOLDORF, 2015).

${ }^{2}$ Para os semioticistas greimasianos, destinador é aquele que convoca o leitor-destinatário, propondo uma ação comunicativa a partir de um referencial. Ele também fornece uma série de programas que estruturam o discurso. Alguns autores, principalmente da análise do discurso crítica e da semiótica discursiva, preferem usar os termos enunciador e enunciatário. Teóricos da comunicação e do jornalismo optam pelo termo editor ou a "voz" representativa da "política editorial", o "pensamento patronal" ou diretivo.
} 
nando-se a maior e mais representativa semanária brasileira e a segunda no mundo. Os padrões empregados pelo enunciador são mais ousados que aqueles percebidos em Época, IstoÉ e Carta Capital. O destinador determina que o enunciador de Veja interfira nas notícias e reportagens, construindo posicionamentos em acordo à programação da agenda midiática. Juízos de valor e conceitos podem resultar da opinião direta do enunciador ou da ênfase às vozes dos interlocutores, as fontes consultadas como especialistas nos mais variados assuntos. Veja defende uma política editorial sedimentada na visão liberalista e democrática de seu destinador, cuja enunciação se revela inicialmente por meio do Manual de Estilo da Editora Abril. É ele quem pavimenta os rumos dos enunciados, concedendo sustentação às ações do destinador sobre o enunciador, e deste sobre o leitor-enunciatário.

A opção pela semiótica greimasiana não visa a percorrer uma teoria conspiratória, mas, longe disso, a apresentar os possíveis efeitos de sentido das leituras e das interpretações dos diálogos entre os títulos, ou sujeitos. Não se pretende aqui desenvolver um método oculto de leitura sob o ponto de vista de uma conjuração secreta, e sim outras formas de leitura, interpretação e compreensão da realidade da informação. Trata-se de um método por meio do qual se proporciona outro ângulo de visualização dos processos de produção e edição do corpus verificado e analisado, bem como do objeto pesquisado em si. A pesquisa contempla a possibilidade de variados modos de leitura do corpus ou, como afirma Oliveira (2002, p. 13), a de fazer os sujeitos interagirem com os objetos e com eles mesmos. A leitura fundamentada nas raízes teóricas da semiótica discursiva torna as interações mais ricas e dinâmicas, facilitando o diálogo entre as partes. Tal assertiva recebe a corroboração de Landowski (2002, p. 4), que ressalta a necessidade de o sujeito se unir a outros sujeitos a fim de alcançarem a realidade semiótica.

É ingenuidade acreditar que os títulos são acessórios dos enunciados midiáticos. Outro mito é imaginar que a produção de títulos obedece a critérios estéticos. Antes de redigir uma matéria, seja ela notícia ou reportagem, deve-se refletir em torno do título, a síntese e a essência do conjunto enunciativo. O título carrega significados ideológicos conectados às determinações do destinador. Seus efeitos de sentido terão implicações sobre o enunciatário. Diante disso, entende-se por que se confere tanta importância na escolha de um editor. Não basta cumprir as rotinas requeridas, tais como a gestão da seção, do tempo e de seus repórteres e demais cooperadores, mas é preciso conhecer de antemão 
o conteúdo selecionável, preparando-o em consonância à regularidade da programação instituída. Ao cumprir seu papel como salvaguarda da ideologia programada, o enunciador-editor evitará a possibilidade de um acidente, ou ruído. Ao reiterar as imposições do destinador-manipulador sobre o enunciador, a fim de que ele cumpra os valores idealizados no discurso, tal atitude será "capaz de levar", segundo Sobral (2005, p. 128), "o enunciatário, seu destinatário, a crer e fazer".

Em um contexto de analfabetos literais e funcionais alcançando pouco mais de cinco por cento da população (TEIXEIRA; MANZANO, 2008, p. 23), o papel educacional dos media na sociedade torna-se nulo, para não dizer irrelevante. $O$ incentivo à politização, ao trabalho honesto, à exigência de transparência apenas dos setores públicos, diluem-se e evaporam diante dos interesses manipulativos de qualquer destinador. A quebra do contrato fiduciário com o enunciatário estimula a desconfiança quanto à relevância da mídia enquanto bastião das liberdades individuais. Ao se sentir traído, manipulado, o enunciatário começa a contestar a credibilidade e o papel da imprensa. As distorções dos parâmetros tradicionais dos fazeres pragmáticos do jornalismo, ou de suas rotinas, percebidas em Veja, servem de mola propulsora para o confronto e interpretação das relações dialógicas entre os títulos de capa e os títulos das entrevistas editadas no espaço topológico das "páginas amarelas", no qual se pretende conhecer como Veja impõe sua programação - a linha editorial - e joga com uma manipulação da sensibilidade reativa do destinatário.

E mais: Como se desenvolve o percurso narrativo? De que modo os sujeitos interagem? Ao interagirem os sujeitos, existe a possibilidade do surgimento de um terceiro sujeito, resultado do diálogo entre eles? Quais seriam os papéis temáticos dos sujeitos envolvidos na programação? Como se expressa a figuratividade ${ }^{3}$ Qual é o papel do enunciador que ratifica a responsabilidade imposta pelo destinador para ele cumprir a axiologia do discurso e construir os efeitos de sentido que atuam sobre o destinatário? De que modo ocorre a estesis, isto é, a construção dos efeitos de sentido, o porquê das coisas, ou o que se passa ao destinatário? Para essa compreensão, recorre-se aos regimes de junção e de união, respectivamente de Greimas e de Landowski, a fim de se perceber o modo pelo qual se determinam os fazeres jornalísticos. Landowski $(2005$, p. 17) denomina esses fazeres de "algoritmos de comportamento", ou seja, o conjunto de instruções para reforçar um papel temático e manter a programação.

\footnotetext{
${ }^{3}$ Figuratividade é o arranjo ou a tela do parecer.
} 


\section{Destinador-manipulador}

De acordo com a engenharia da notícia, o primeiro filtro a servir os interesses do destinador-manipulador é a pauta. Na reunião da qual participam os representantes dos destinadores e enunciadores, isto é, diretoria, chefias de redação e de reportagem, editores, articulistas e repórteres, a teia temática dos enunciados sob programação começa a ser tecida. Aqui se decide o destino de indivíduos e instituições, públicas ou privadas, indicam-se fontes pessoais, institucionais e documentais, direcionando os pontos de vista requeridos, bem como sublinhando os objetivos, as prioridades da programação, sempre conectada aos axiomas da mídia. Trata-se de uma linha tênue, que necessita de atenção ao investigar os parâmetros envolvidos. Até mesmo Greimas (2002, p. 84) considera difícil delinear essa faixa divisória entre o que se observa e o que se deseja perceber. Os enunciadores articulam com mais qualidade as capas das semanárias do que as primeiras páginas dos diários, combinando as linguagens verbais às não verbais, solidificando os preceitos da programação da agenda midiática. A esse método, Hernandes (2006, p. 187) denomina de "estratégia de arrebatamento" ou de "gerenciamento da atenção mobilizada". O objetivo do enunciador visa a capturar a atenção do enunciatário.

Ao apresentar o resultado do artigo anterior na Intercom 2010, vozes críticas e pouco reflexivas consideraram coincidência as análises a respeito dos títulos de capa e das páginas amarelas de Veja. Todavia, o diálogo entre os sujeitos - padrão adotado pelo destinador - se repete há quase cinquenta anos. Não se trata de casualidade encontrá-los em quase todas as publicações nas quais as entrevistas se fizeram presentes nas páginas amarelas. Para tanto, examinaram-se mais de duas mil capas e páginas amarelas entre 1970 e 2009, recortando-se apenas duas edições para este artigo. Necessita-se, então, semiotizar esses recortes para aprofundar a compreensão de tais relações. À semiótica concerne conceituar a percepção de um mundo que emerge além do sensível. Carmo Jr. (2005, p. 152) referenda tal panorama afirmando que "uma análise semiótica não pode limitar-se apenas a descrever adequadamente seu objeto. Ela precisa ir mais além, apontando para perspectivas mais generalizantes, aplicáveis a outros objetos, em outros contextos". A falta de percepção de muitos, deixa-os semelhantes aos morcegos, cujo mundo se encontra quase sempre de cabeça para baixo. Cabe à semióti- 
ca extirpar a mentalidade quiróptera. Carmo (2007, p. 36) concorda que “a sensação não pode ser estudada por meio de um juízo intelectual, por uma consciência distanciada que a toma como objeto de estudo".

Ao determinar que Veja não pode ser descrita como um "produto", verifica-se aqui a ação sancionadora de um sujeito julgador - no caso, o então destinador Roberto Civita, ex-presidente do Grupo Abril, morto em 26 de maio de 2013 - que modaliza pelo querer e poder o enunciador-editor. $\mathrm{O}$ atropelamento das normas exaradas no Manual de Estilo pelo destinador demonstra apenas que os limites do reconhecimento do Outro diferente não precisam ser respeitados pelo enunciador quando este recebe ordens contrárias da hierarquia vertical, hoje comandada pelo CEO Giancarlo Civita - exemplo dessa quebra dos limites fronteiriços se verificou com a publicação da capa da edição de 4 de novembro de 2015, na qual o ex-presidente Luiz Inácio Lula da Silva aparece em imagem sangrada - ou ampliada - tal como um presidiário. Ao analisar a manipulação, Landowski (2005, p. 38) realça as relações entre destinador e enunciador como aquelas sobre as quais o destinador-manipulador faz valer sua programação, pois precisa de um sujeito capaz de reproduzir suas propostas, e este sujeito é o enunciador-editor, representado ora pelo diretor de Redação, ora pelos editores de capa e das páginas amarelas.

Em virtude de não haver concessão para impressos no Brasil, jornais e revistas podem atuar livremente. Todavia, nem todos demonstram plena autonomia em relação às instituições públicas. Os pacotes de editais de concorrência, de concursos, anúncios de estatais, secretarias, ministérios, autarquias, propagandas governamentais, eleitorais, partidárias, ideológicas ou mesmo de autopromoção de indivíduos servem de mote para capturar e fidelizar os fazeres jornalísticos, as ações midiáticas. Quanto mais crescem os proventos de tais relações comerciais e políticas, maior a dependência demonstrada pela mídia no tocante aos discursos oficiais. A reciprocidade de afagos e tratamentos amistosos e interesseiros "interfere na independência editorial de uns e corrobora o posicionamento político de outros" (HOLDORF, 2015, p. 29).

Não são marqueteiros os autores da capa de Veja. Ela também não é desenvolvida com fins exclusivamente comerciais. Trata-se de uma ação política. De acordo com Prado (2005, p. 43), "em geral a sociedade civil não tem poder em Veja, pelo menos nas reportagens de capa", cujo discurso "modaliza o agir do leitor", mapeando os passos que ele "deve 
dar (ação) para saber X, fazer Y e ter sucesso". A semiótica narrativa, segundo Landowski (2005, p. 15), explana essa questão sob o prisma das interações em suas duas formas, a programação e a manipulação, a primeira regida pelos princípios de regularidade, e a segunda pelos princípios de intencionalidade estratégica.

A mídia não apenas informa, mas constrói, segundo Prado (2005, p. 41), "mapas cognitivos para seus leitores, orientando-os para a ação e dirigindo suas formas de ler, situando-os performativamente em certas posições de sujeito enquanto enunciatários". Contrastados, os sujeitos "título-manchete" e "título de página amarela" aprofundam o significado percebido nessa relação de diálogo e representam o ponto de vista axiológico do destinador. $\mathrm{O}$ enunciatário precisa de muita atenção para capturar os valores do destinador expostos no significado da relação entre os títulos de capa e das páginas amarelas. Se a construção do enunciado se processa pelo título, então ele demonstra relevância, cujo intuito permite ao enunciador enlaçar o enunciatário-leitor, observando com destaque aqueles que ocultam um sujeito da enunciação ideológica implícito, ou o "ser oculto", conforme Greimas (2002, p. 412) defende. Veja se encaixa perfeitamente nesse recorte. Ela emprega artifícios dissimulados para posicionar seu conteúdo ideológico diante do enunciatário-leitor. Ao mencionar o pensamento de Greimas, Sobral (2005, p. 126) destaca que o discurso produzido pelo sujeito da enunciação revela o efeito de sentido de veridicção. Trata-se da manipulação do enunciador sobre o enunciatário, cujo enunciado se pretende fazer parecer veraz a partir do contrato de fidúcia, instaurando-se assim o simulacro da verdade.

\section{Sujeitos em relação ${ }^{4}$}

Como exemplo do processo de semiotização das narrativas jornalísticas da semanária, destacam-se dois recortes: o início do mandato do presidente norte-americano Barack Obama e os efeitos do aquecimento global. Em 18 de março de 2009, Veja apresenta a capa com uma linguagem sincrética (Figura 1).

\footnotetext{
${ }^{4}$ Para este artigo, selecionaram-se duas edições de épocas mais distantes - de 2007 e 2009 - a fim de evitar qualquer má-interpretação ou crítica de natureza política diante das análises. Não existe nenhuma intenção ideológico-partidária por parte do autor. 0 que importa é o modo de compreensão por meio da semiotização das narrativas, independentemente do tempo nos quais os fatos se sucederam. Daí a opção por negar um corpus publicado em períodos mais recentes.
} 


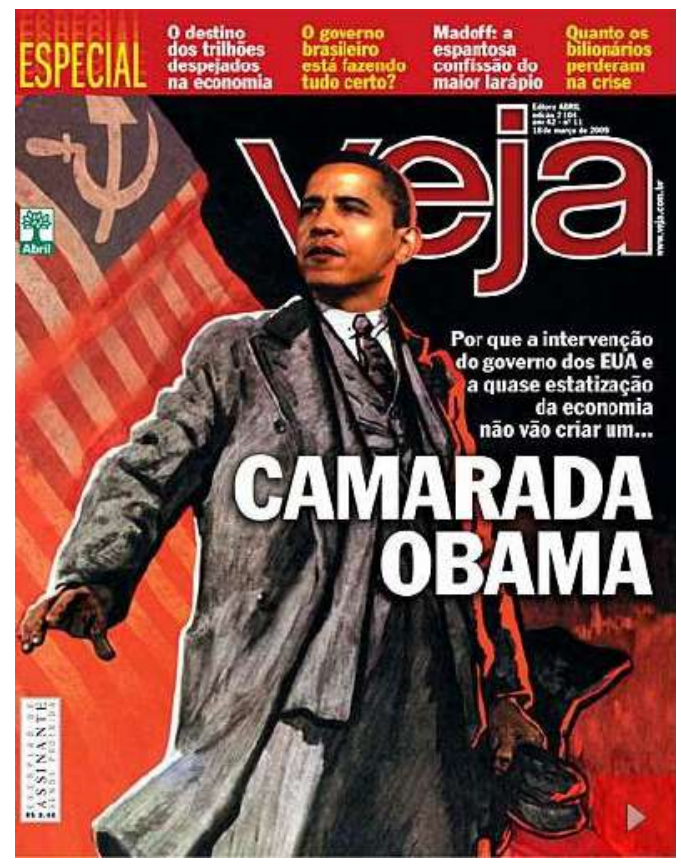

Figura 1: Primeiro sujeito.

Nela, o presidente Obama veste um terno e sobretudo escuros, segurando um cachecol à mão esquerda, similar à imagem dos ex-líderes políticos da União Soviética, destacando-se graças à luz que ele reflete e figurativiza o retrato idolatrado, respeitado e temido dos antigos líderes bolcheviques. Sobre o fundo escuro, logo atrás de Obama, vislumbra-se a distorcida bandeira dos Estados Unidos. No lugar de estrelas brancas em fundo azul, no canto superior esquerdo emergem a foice e o martelo, símbolos presentes em bandeiras de alguns países comunistas, entre elas a do ex-império soviético, principal inimigo dos Estados Unidos durante a Guerra Fria (1945-91). O sujeito-manchete modalizador detém o saber e tenta esclarecer ao leitor os motivos da intervenção do governo norte-americano sobre a economia e o risco de estatização, cujas consequências poderiam transformar Obama em um líder totalitário, um "camarada", expressão de tratamento muito usada entre os comunistas, traduzida do russo tovarichtche (товарище). Não obstante o enunciador demonstrar a força dos Estados Unidos, expressa no enunciado, o sujeito-manchete discorda da possibilidade autoritária de um governante centralizar poderes decisórios não contemplados em nenhum de seus antecessores ao se referir "à quase estatização da economia", e que 
eles, os norte-americanos, "não vão criar" um ditador. As imagens de Obama e da bandeira deixam o sujeito $1 \mathrm{em}$ disforia, pois se trata de uma possível quebra de normalidade para o enunciatário. O estado eufórico, desejado, aparece quando ocorre o sincretismo das linguagens verbo-visuais presentificadas na enunciação.

Algumas páginas adiante, nas "amarelas", segue a entrevista com o arcebispo de Olinda, José Cardoso Sobrinho, procurando elucidar a excomunhão da equipe médica cujo único "ato pecaminoso", aos olhos da Igreja Católica, se ateve a salvar uma criança de nove anos, depois de praticar dois abortos cirúrgicos (Figura 2).

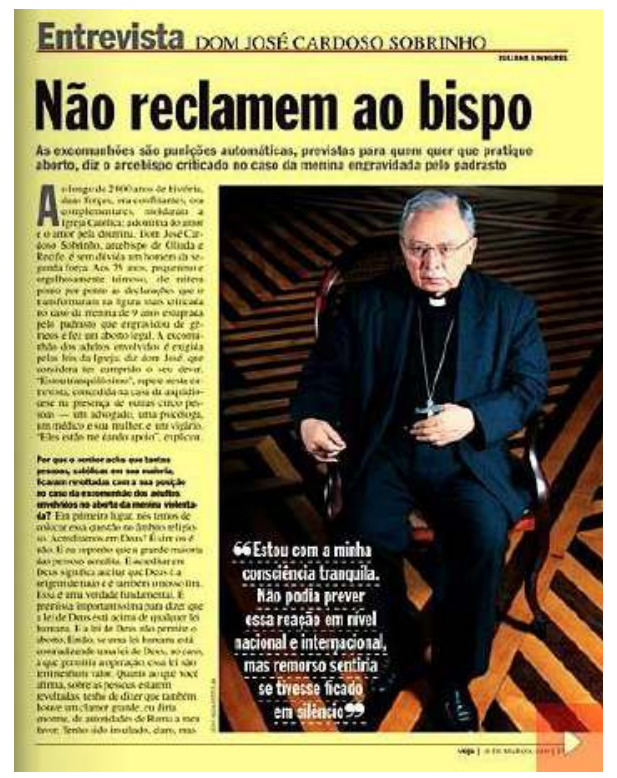

Figura 2: Segundo sujeito.

O segundo sujeito enuncia para que "Não reclamem ao bispo", reiterando à interpretação e confrontando as ideias do religioso às ações de Obama, instalando novos paradigmas, que o indisponibilizam diante dos críticos e aproxima cada vez mais adeptos de sua visão de mundo, conforme enunciados expressos na janela superior da capa. Semelhante a Obama, o arcebispo se veste de tradicional indumentária, que instala o respeito e o medo, sobressaindo-se os detalhes em branco no colarinho e o crucifixo à mão. Ele se assenta sobre uma cadeira num salão, cujo piso com detalhes retilíneos em cores contrastantes de madeira clara e escura constrói um ambiente palaciano e lhe confere poder. Este poder 
se concretiza com a fala do religioso destacada em branco sobre o canto inferior esquerdo da fotografia. Ele afirma conservar a consciência tranquila, mesmo diante da excomunhão da equipe médica, não obstante a reação pública e a repercussão negativa além-fronteiras.

Deve-se ressaltar que o enunciador não o trata como arcebispo no título, mas o rebaixa à condição de bispo, hierarquicamente inferior. Somente quando se confrontam os sujeitos, percebe-se que o enunciador também inferioriza o papel de Obama no cenário político, de presidente da nação mais poderosa do planeta a camarada de um império abalado pela crise econômica, praticamente falido. De acordo com Greimas (2002, p. 75), o encadeamento de escolhas faz com que se construa um objeto de valor. O encontro dos sujeitos 1 e 2 faz com que eles se transformem em actantes, criando o efeito de sentido. Essa necessidade de amálgama entre os sujeitos - títulos de capa e das páginas amarelas - reflete a falta de sentido em si mesmo de cada título isolado da totalidade, modalizando-se um novo sentido. "Ou a informação produz sentido", assevera Baudrillard (1991, p. 103), ou "não consegue compensar a perda brutal de significado em todos os domínios". Se acaso Obama se insurgir em questões morais, religiosas, dogmáticas, que ninguém recorra aos líderes religiosos, pois tanto esses como a própria massa lhes asseguram uma base de sustentação.

Ao longo da narrativa da reportagem de 11 de abril de 2007 (Figura 3), o enunciador demonstra o paradoxo entre o sujeito-manchete (1) "O alerta dos polos" e o sujeito-título (2) "O risco é zero" da entrevista com o então ministro da Justiça, Tarso Genro (2007-2010) (Figura 4). O ministro defende e sustenta a impossibilidade de retrocesso institucional no País. Todavia, quando os sujeitos se unem, a enunciação dos valores referendados pelo enunciador contraria o alarmismo dos cientistas que acreditam em uma iminente catástrofe devido à destruição dos recursos naturais do planeta. 


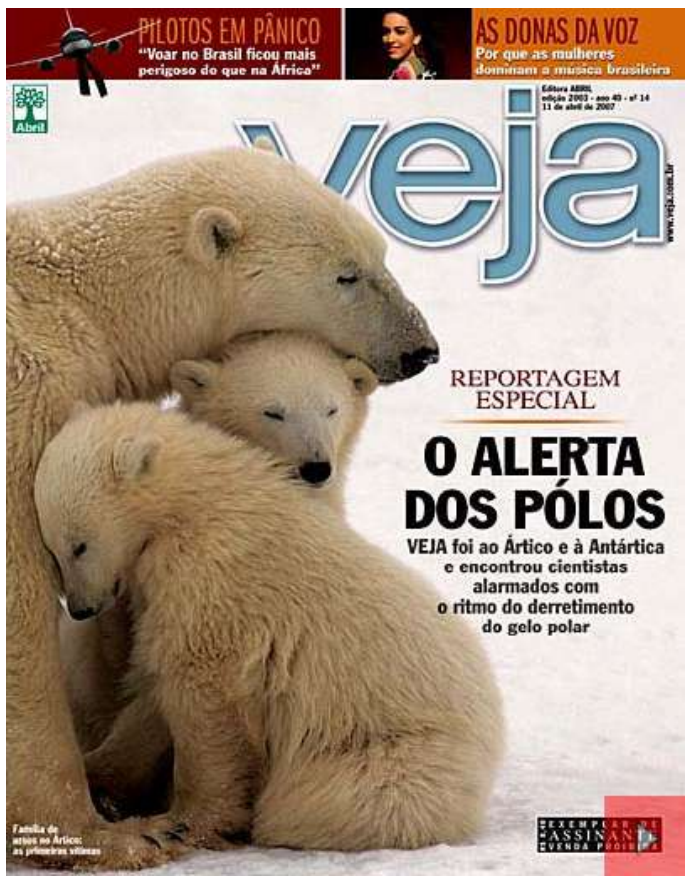

Figura 3: Sujeito-manchete.

O sujeito 1 descreve que o enunciador visitou os polos. Essa ação performática do fazer se expressa em dois tipos de manipulação. A primeira, visual, com a imagem da ursa e seus dois filhotes encostados uns aos outros e de olhos fechados, como se estivessem cansados, fraquejados pela fome, desistindo da própria existência. $\mathrm{O}$ fundo branco acentua a solidão do ambiente topológico das primeiras vítimas do aquecimento, a infinitude do gelo que não deveria derreter, a neve eterna, figurativizando a alva pureza de ursos de pelúcia, inermes diante da destruição provocada pelo homem, seu predador. Parafraseando Floch (1985, p. 18), as cores não são o mais importante em si, mas suas qualidades e o efeito de sentido delas sobre os sujeitos. O fundo branco é coberto pela figura dos ursos, no desejo volitivo de impactar o enunciatário. Aqui se dá a manipulação por sedução. O enunciatário é induzido a se comover com a situação de quase extinção da espécie do urso polar. A manipulação por intimidação se verifica no enunciado enaltecendo os cientistas em alarma com a velocidade do derretimento da camada polar.

Enquanto o sujeito 1 escancara o desespero dos pesquisadores, o sujeito 2 salienta a ordem institucional garantida por Genro. A linguagem verbal também recebe o reforço da linguagem visual. A mão esquerda 
fechada do ministro causa o efeito eufórico, pois endossa a segurança na impossibilidade de um retrocesso na natureza democrática conquistada pelo Brasil pós-ditadura. A manipulação dos sujeitos para manifestar sua programação é uma ordem que o destinador não deixa de emitir ao enunciador. $\mathrm{O}$ amálgama de temáticas políticas à ecologia se ajusta às determinações do destinador em defesa de interesses conectados aos princípios reguladores, sustentando carregar em seu bojo as diretrizes de verdade. Bauman (1998, p. 143) explica essa noção de verdade como pertencente "à retórica do poder", uma forma de se "insinuar que o outro lado que está errado", estabelecendo regularmente sua supremacia. Assim, o destinador solidifica as bases ideológicas que fortalecem sua crença, o fazer-crer intencional, na impossibilidade de catástrofe ecológica, fato desvendado em reportagens posteriores à conferência de Copenhague, em dezembro de 2009. Em entrevista ao Programa do Jô, o climatologista Ricardo Felício sustentou que "o aquecimento global é uma mentira" e que jamais existiram provas para comprovar tal fenômeno.

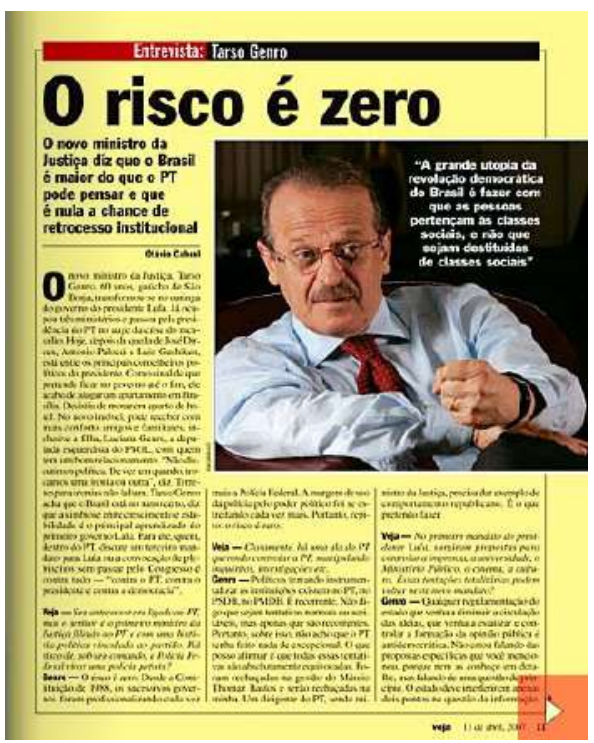

Figura 4: Sujeito Páginas Amarelas.

\footnotetext{
${ }^{5}$ Programa do Jô. Disponível em: < http://programadojo.globo.com/platb/programa/2012/05/02/ ricardo-augusto-felicio-afirma-que-o-aquecimento-global-e-uma-mentira>. Acesso em: 7 mai 2010. Ver também tese: FELÍCIO, Ricardo A. Climatologia dinâmica da Antártida: ciclones extratropicais que atuaram nos verões e invernos de 2001 a 2006 na região da Península Antártica (Tese de Doutorado em Geografia Física) - USP, 2007. Outras informações a respeito da temática podem ser assistidas por meio dos endereços: <http://www.youtube.com/watch?v=Pqz4yMzbwF0\&feature=related> <http://www.youtube.com/watch?v=0julx-PYZn8> e <http://www.youtube.com/watch?v=FxOlj53ILDE\&feature $=$ g-vrec $>$.
} 
O emprego de técnicas e métodos para abordar temáticas como a do meio ambiente recebe a assinatura do enunciador (MANZANO e PADIAL, 2009, p. 21), o qual despreza os defensores do catastrofismo, justificando os elementos valorativos presentes na enunciação. A temática a respeito do meio ambiente não passa de um pretexto para a inserção de outros conceitos ancorados pelo destinador. Hernandes (2006, p. 201) ressalta a astúcia do enunciador em direcionar seu conteúdo a apenas um enunciatário, estabelecendo certo ritmo entre enunciados e entre temáticas diferenciadas, sem perder sua identidade.

\section{Considerações finais}

Ao perceber os efeitos de sentido edificados pela programação editorial do destinador de Veja, existem indícios tornando irrefutável que o mais destacado título de revista do Grupo Abril manifesta parte de sua ideologia de modo perspicaz, julgador e manipulador na construção e conexão das diferentes isotopias, sujeitos-títulos da capa e das páginas amarelas. Diferentes formantes cromáticos - o preto e o branco - provocam o efeito do medo, temor do fim da democracia e inquietação diante da destruição do planeta. O tempo de percurso na busca de si mesmo se revela como verdade, segundo Greimas (2002, p. 43 e 51), tornando o objeto pleno de ocorrência de sentido e construindo o próprio sentido, a estesis, em direção ao inteligível. Aqueles que refutam essa tese têm de responder convincentemente o que acontece em Veja aos enunciatários-leitores. Afinal são quatro décadas de construção de simulacros de verdade, que merecem até mesmo ser enaltecidos, mais pela criatividade dos enunciadores-editores do que pela ingerência e competência do destinador em defesa de democracia.

Constata-se, também, o teor doutrinário-axiológico contido no manual de redação e no direcionamento hierárquico das pautas pelo destinador. Nesse meio, poucos fazem jornalismo somente por altruísmo. Acima do compromisso social se posiciona o pensamento norteador das ações, cujas nuances podem ser eventualmente detectadas em novos estudos confrontando outros objetos midiáticos. Qualquer leitura deve ser antecedida de um espírito crítico quanto aos propósitos da mídia. Interessante ressaltar a necessidade de se aprofundar esse tema na semiótica discursiva, abordando outras nuances aqui não trabalhadas ou devidamente aprofundadas, como o acidente e o ajustamento, os elementos formantes da enunciação e o modelo greimasiano de produção 
do sentido, ou o percurso das estruturas fundamentais, narrativas e discursivas - como se desenvolvem os percursos narrativos ou a sequência hierárquica de programas narrativos conectando os títulos de capa e das páginas amarelas.

É bem verdade que nem todos os problemas foram respondidos neste artigo, mas algumas conclusões já podem ser alinhavadas: 1) Os títulos de capa e das páginas amarelas são enunciados cuja subjetividade é comandada por uma intencionalidade, característica do regime de manipulação. Como sujeitos, os títulos analisam o querer, entrando na subjetividade do Outro, criando, então, o percurso narrativo e fazendo o outro sujeito querer e crer. 2) Pode-se deduzir, desse modo, que o destinatário teria condições de perceber os efeitos de sentido e as intenções do destinador ao apreender o diálogo entre os sujeitos (títulos) pela figuratividade. Essa tela do parecer o predispõe a sintonizar-se no percurso do enunciador para posicionar-se frente às coberturas do destinador Veja e, mesmo nelas, quando o destinatário é conduzido a estar em ato afetado pelos efeitos de sentido postos no enunciado para ele operar. 3) O jornalismo praticado por Veja expõe sua credibilidade ao risco e, por extensão, a própria democracia. Ao tentar manipular o enunciado direcionado ao enunciatário, Veja enfraquece o conjunto de forças midiáticas, escancarando a porta para que outras forças, antidemocráticas e autoritárias, ocupem o espaço conquistado anteriormente pela democracia.

\section{REFERÊNCIAS}

BAUDRILLARD, Jean. Simulacros e simulações. Lisboa: Relógio d’Água, 1991.

BAUMAN, Zygmunt. O mal-estar da pós-modernidade. Rio: Jorge Zahar, 1998.

CARMO, Paulo S. Merleau-Ponty: uma introdução. São Paulo: Educ, 2007.

CARMO JR., José R. Semiótica e futebol. In: LOPES, Ivã C. et al. Semiótica: objetos e práticas. São Paulo: Contexto, 2005.

CONTI, Mario S. Notícias do Planalto: a imprensa e Fernando Collor. São Paulo: Cia. das Letras, 1999. 
FLOCH, Jean-Marie. Petites mythologies de l'oeil et de l'esprit: pour une sémiotique plastique. Paris-Amsterdam: Hadès-Benjamins, 1985.

GREIMAS, Algirdas J. Da imperfeição. São Paulo: Hacker, 2002.

HERNANDES, Nilton. A mídia e seus truques: o que o jornal, revista, TV, rádio e internet fazem para captar e manter a atenção do público. São Paulo: Contexto, 2006.

HOLDORF, Ruben D. A visão editorial da Veja revelada nas entrelinhas e nos títulos de capa e das páginas amarelas. Acta Científica - Humanas, Unasp, Engenheiro Coelho, n. ${ }^{\circ} 16,2009$. p. $25-38$.

HOLDORF, Ruben D. Engenharia do discurso: a mídia e o Outro e suas implicações no derretimento da democracia no subcontinente sul-americano. Saarbrücken: NEA, 2015.

LANDOWSKI, Eric. Les interactions risquées. Limoges (France): Pulim, 2005.

LANDOWSKI, Eric. Presenças do outro. São Paulo: Perspectiva, 2002.

MANZANO, Rodrigo; PADIAL, Karina. Superlativismos - O cérebro de Veja. Revista Imprensa, São Paulo, Jan./Fev. 2009. p. 18-23.

OLIVEIRA, Ana C. Prefácio. In: GREIMAS, Algirdas J. Da imperfeição. São Paulo: Hacker, 2002. p. 9-14.

PRADO, José L. A. O leitor infiel diante dos mapas da mídia semanal performativa. In: Fronteiras - estudos midiáticos, Unisinos, São Leopoldo, 2005, n. ${ }^{\circ}$ 1. p. 39-46.

SOBRAL, Adail U. A relação entre enunciador e enunciatário num discurso de Plínio Salgado. In: LOPES, Ivã C. et al. Semiótica: objetos e práticas. São Paulo: Contexto, 2005.

TEIXEIRA, Fabrício; MANZANO, Rodrigo. A gramatura do papel-jornal. Revista Imprensa, São Paulo, 2008, agosto 2008, n. ${ }^{\circ}$ 237. p. 23-8. 